\begin{tabular}{|c|c|c|}
\hline & Int.J.Curr.Microbiol.App.Sci (2021) 10(12): 169-176 & \\
\hline & $\begin{array}{l}\text { International Journal of Current Microbiology and Applied Sciences } \\
\text { ISSN: 2319-7706 Volume } 10 \text { Number } 12 \text { (2021) } \\
\text { Journal homepage: http://www.ijcmas.com }\end{array}$ & 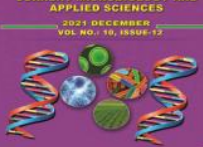 \\
\hline $\begin{array}{l}\text { EXCELLENT } \\
\text { PUBLISHERS }\end{array}$ & & \\
\hline
\end{tabular}

Review Article

https://doi.org/10.20546/ijcmas.2021.1012.019

\title{
Review on Effect of Hurdle Technology in Food Preservation
}

\author{
Ann Annie Shaju* and M. G. Anjaly \\ Department of Processing and Food Engineering, Kerala Agricultural University, Thrissur, \\ Kerala, India \\ *Corresponding author
}

\section{A B S T R A C T}

\section{Keywords}

Pathogenic microorganisms, food preservation techniques, hurdles

\section{Article Info}

Received: 05 November 2021 Accepted:

25 November 2021

Available Online:

10 December 2021
When considering food stability the microbial, chemical and sensory qualities must taking into consideration. To achieve these, appropriate preservation measures must be taken to the level that the activities of microorganisms will be overcome. The microbial stability and safety of the most traditional and processed foods is based on a combination of several preservation factors (called hurdles), which the microorganisms present in food are unable to overcome. Hurdles use in food can be physical, physicochemical or microbiologically derived. The main objective of hurdle technology is food preservation, but in addition, many hurdles were reported to improve sensory attributes. Many findings revealed that combination of preservatives at lower concentrations discourage microbial activities more than single preservative at higher concentration. In this review general introduction of hurdle technology was given, also basis on food spoilage and preservation. Principles, application, advantages and effects of hurdles on food quality were also reviewed. Hurdles classification with examples was also stated. Special emphasis was given to contributions from other researchers on the application and effectiveness of hurdle technology in maintaining microbiological, chemical, sensory and physical qualities of processed foods.

\section{Introduction}

Primarily, food preservation techniques are an inseparable part of production of foodstuffs in regards with overcoming pathogens with respect to extending shelf life as an often controversial issue, food scientist attempted to achieve to novel non-destructive food production methods, modern method of quality assessment accompanied by least occurring nutrient damages. Hurdle technology is a process of rendering food to be free from spoilage and pathogenic microorganisms by the combination of one or more preservation methods. The spoilage and pathogenic microorganisms have to pass through these individual approaches called "hurdles" for maintaining their activity in food products (Subha, 2013). Hurdle application of different treatments offers synergistic advantage compared to separate using of the individual treatment (Bazhal et al., 2003). 
The concept of hurdle technology was first introduced by Lothar Leistner (1978). More recently out of the comprehension of the hurdle technology new concepts for food safety have emerged (Leistner, 1997). Hurdles ensures microbial safety in food and maintained its nutritional and organoleptic parameters for consumer preference (Subha, 2013). The main theory of bringing hurdle technology up is severity of applying one preserving factor which can lead to degrade nutritional quality as a result of damages may occur to food substances (Rahman, 2012).

Combining inhibitory factors can result in a significant improvement in securing microbial safety and stability as well as the sensory and nutritional quality of foods (Juneja, 2003).

These include manipulation of factors such as temperature, water activity and acidity, as well as processes such as gas packaging and high pressure processing. The aim is to interfere with several different mechanisms within microorganisms simultaneously. This multitargeted approach allows effective use of mild techniques (IFIS, 2005).

\section{Microbiological Food Spoilage}

Food Spoilage is deterioration of quality parameters of food by chemical, physical or microbial means (IFIS, 2005). For microbial food spoilage to occur, several events need to take place in sequence. Microorganisms have to get into the food from one or more sources, the food environment ( $\mathrm{pH}$, aw, O- $\mathrm{R}$ potential, nutrients, inhibitory agents) should favour growth of one or more types of these contaminating microorganisms, the food must be stored (or abused) at a temperature that enables one or more types to multiply, and finally, the food must be stored under conditions of growth for sufficient length of time for the multiplying microbial types to attain the high numbers necessary to cause the detectable changes in a food (Bibek, 2005). It is clear that the microbial safety of food can be granted when the overall processing, including the production of raw materials, distribution and handling by the consumers are taken into consideration. Therefore, the microbial quality assurance of foods is not only a matter of control, but also a careful design of the process chain (Hofstra et al., 1994).

\section{Principles of Food Preservation}

Food preservation is a process of maintaining the original quality or existing state of food by treatments that will prevent its spoilage or deterioration (IFIS, 2005). It implies putting microorganisms in a hostile environment in order to cause their death (Oladapo et al., 2014). When food is to be stored for a prolonged period, use of preservatives is essential in order to maintain its quality and flavour. Their use prevents spoilage of foods due to the growth of bacteria and fungi. They also maintain the quality and consistency of the foods, along with its palatability and wholesomeness.

Preservatives also maintain nutritional value, control appropriate $\mathrm{pH}$ and enhance flavour (Arora, et al., 2014). The disturbance of the homeostasis of microorganisms is the main mechanism of food preservation (Leistner, 2010). Traditional methods for acceptable preservation of foods include heating, chilling, freezing, drying, curing, salting, preserving with sugar, direct acidification, natural fermentation, modified atmosphere packaging and smoking (Juneja, 2003).

Chemical preservatives may be injurious when used at higher concentrations. Arora et al., (2014) reported that at higher concentration benzoates can trigger allergies such as skin rashes, asthma and can also causing brain damage. He also reported that sodium chloride 
when used in high amount in' meats and fish can lead to high blood pressure, kidney failure, stroke and heart attack.

\section{Hurdle Technology}

Hurdle technology is a method of ensuring the safety of foods by eliminating or controlling the growth of pathogens, making the food safe for consumption and extending its shelf life through the application of a combination of technologies and approaches. The stability and safety of foods depends on various preservation factors. Depending on the type of product, the type and intensity of the hurdles will vary case by case. The effects produced by the combination of these hurdles is called hurdle effect.

\section{Principles of Hurdle Technology}

The microorganisms present ("at the start") in a food product should not be able to overcome ("jump over") the hurdles present, otherwise the food will spoil or even cause foodpoisoning (Leistner, 1994). The most important hurdles commonly used in food preservation are temperature (high or low), water activity (aw), acidity (pH), redox potential (Eh), preservatives (nitrite, nitrate, sorbate, sulfite etc) and competitive microorganisms (lactic acid bacteria) (Leistner, 2011).

The concept is that for a given food the bacteria should not be able to "jump over" all of the hurdles present, and so should be inhibited. The microbial stability and safety as well as the sensory and nutritional quality of most preserved foods are based on a combination of several empirically applied preservative hurdles (Leistner, 2011), which the microorganisms present in the food are unable to overcome. The physiological responses of microorganisms during food preservation such as homeostasis, metabolic exhaustion, and stress reaction are the basis for the application of hurdle technology. Use of combined hurdles could increase the disturbance of homeostasis and cause the metabolic exhaustion of microorganisms. Since different hurdles have different spectra of antimicrobial action, the combined hurdles could attack microorganisms in different ways and may increase synergistically the effectiveness of preservation ('multitarget preservation') (Leistner, 2011). The mechanisms by which the combination of factors, or hurdle concept, works is that; when two target microorganisms $a$ and $b$ can grow when preservation methods $\mathrm{X}, \mathrm{Y}$, or $\mathrm{Z}$ are used as individual hurdles. Then, if $\mathrm{X}$ and $\mathrm{Y}$ are combined, the growth of a is arrested, and when $\mathrm{X}, \mathrm{Y}$, and $\mathrm{Z}$ are used in combination, both microorganisms fail to grow (Bibek, 2005).

Hurdle effect is of fundamental importance for the preservation of food, since the hurdles in a stable product control microbial spoilage and food poisoning as well as control of fermentation (FOA, 2006). The hurdle concept illustrates only the well-known fact that complex interactions of preservative factors are significant for the microbial stability of foods. From an understanding of the hurdle effect, hurdle technology has been derived, which allows improvements in the safety and the quality as well as the economic properties of foods, by an intelligent combination of hurdles (Leistner, 1994). A synergist effect could work if the hurdle in a food hits different targets (e.g., cell membrane, DNA, enzyme systems, $\mathrm{pH}$, aw, Eh) within the microbial cell, and thus disturbs the homeostasis of the microorganisms present in several aspects. Therefore, employing different hurdles in the preservation of a particular food should be an advantage, because microbial stability could be achieved with a combination of gentle hurdles. In practical terms, this could mean that it is more 
effective to use different preservatives in small amounts in a food than only one preservative in large amounts, because different preservatives might hit different targets within the bacterial cell, and thus act synergistically (FOA, 2006).

The hurdle includes temperature, water activity, $\mathrm{pH}$, redox potential, modified atmosphere, organic and inorganic preservatives etc. (FOA, 2006). The intensity of the hurdle is ascertained and controlled according to the type of spoilage microorganism(s) and regulated as per consumer safety and preference without sacrificing the quality and appearance of the final food product (Subha, 2013). The different parameters or factors that are used in combination include intrinsic factors (e.g., aw, $\mathrm{pH}$, Eh, and natural inhibitors), processing factors (e.g., heating, drying, fermentation, and preservatives), and extrinsic factors (e.g., temperature and aerobic or anaerobic environment). Competitive flora (e.g., lactic acid bacteria) and non-thermal processing methods can be added to them (Bibek, 2005).Proper combination of hurdles will lead to destruction of the microbes and can prevent their further growth. It also ensures microbial safety in food thereby maintaining its nutritional and organoleptic parameters for consumer preference (Subha, 2013).

\section{Hurdle Factors}

In traditional cases of food preservation, addition of sugar to produce jams, heating, deposition of antimicrobial agent from smoking onto food surface and so forth are considered hurdles. Since aforementioned factors have flavour affecting properties contribute in sensory properties of final products. To achieve a good level of shelf life in terms of extending shelf life using hurdle technologies, they must arise at different stages in orders.
Depending on the condition of product, a different series of hurdles, to overcome satisfactorily the number of pathogens, adequate level of minimizing the loss of nutrients can be used, but it should be noted that in practice, they can operate simultaneously, synergistically, sequentially.

Hurdle factors used in food preservation includes heating $(\mathrm{F})$, chilling $(\mathrm{t})$, low water activity (aw), acidification $(\mathrm{pH})$, low redox potential (Eh), preservatives (pres.), vitamins (V), nutrients (N) (Leistner L and Gorris LGM, 1994.)

\section{Types of Hurdles}

More than 60 potential hurdles for foods of plant and animal origin, which improve the microbial stability and/or the sensory quality of these products have already describe, and the list of possible hurdles for food preservation is by no means complete (Leistner, 2011).

\section{Physical Hurdles}

Most hurdles under this heading are processes used in food manufacturing. When using processes intended to kill microorganisms, it is necessary to protect the food product against (microbial) recontamination after processing, this includes: heat processing, manipulation of storage temperatures, irradiation, electromagnetic energy, photodynamic inactivation, ultrahigh pressure processing, ultra sonication and packaging (Leif, 1994).

\section{Physicochemical Hurdles}

Hurdles categorised under this heading include water activity (aw), $\mathrm{pH}$, redox potential $(\mathrm{Eh})$, salt $(\mathrm{NaCl})$, nitrite $(\mathrm{NaNO} 2)$, carbon dioxide $(\mathrm{CO} 2)$, oxygen $(\mathrm{O} 2)$, ozone (O3), organic acids, spices and herbs, sulphite 
or SO2, smoking, ethanol, maillard reaction products (MRPs) and lysozyme (Leif, 1994).

\section{Microbiologically Derived Hurdles}

Hurdles under this class are; competitive flora, starter cultures, bacteriocins and antibiotics (Leif, 1994).

\section{Applications of Hurdle Technology}

Hurdle technology concepts have been adopted by various research investigators for the processing of various food products. Hurdle technology can be applied to wide categories of food which include; dairy products, fresh fruits and vegetables, fruits derived products, animal products (Aditya and Nida, 2015). The technology have a broad application in production Ready-to-Eat foods and production of edible coating. Some preservatives at high concentrations represent chemical hazards; a combination of chemical preservatives with other preservation methods is useful. Proper application of combined methods gives stable products, prevents the undesired side-effects of each individual treatment, saves energy and lowers the required concentration of added preservatives (Pokorn, 1994). Many researchers reported that combination of different hurdles at lower concentrations offer more resistance to microbial activities than individual hurdles used at higher concentrations. Different preservatives might hit different targets within the microbial cell and act synergistically (Sujatha, 2014).In the preservation of jams and jellies, for which high heat, low $\mathrm{pH}$ (of fruits), low aw (sugar in fruits and added), and anaerobic packaging are used to reduce microbial numbers as well as the growth of survivors (Bibek, 2005). Anurag et al., (2013) reported that application of radiation to intermediate moisture products dried by infrared, and use of 400 gauge polythene bag will provide effective retention to nutrient up to six months under ambient storage. (Abdullahi, et al., 2016) reported that combination of $4 \%$ sucrose, $0.1 \%$ citric acid, $0.1 \%$ sodium benzoate and use of HDPE as packaging material eliminates the growth of Salmonella spp. and Staphylococcus spp. during ambient storage of Kilishi (West African traditional dried meat product. Addition of both vinegar and sake was found to be an efficient means of improving the microbial stability of the sous vide packaged seasoned beef product stored at 8 and 200C. Combined addition of vinegar and sake may be considered as a possible alternative with minimal loss of organoleptic quality when longer storage is required like usual use conditions of sous vide packaging (Jae, et al., 2006). Addition of $3 \% \mathrm{Nacl}$ and $0.3 \%$ citric acid on fresh coconut gratings extend it shelf life by one month under ambient conditions and by three months under refrigeration conditions (Gunathilake, 2006). (José, et al., 2008) reported that addition of ascorbic acid, potassium sorbate, and sodium bisulphite into sugar syrup can retain the colour of fresh mango slice for a period of 30 days.

Jyoti, et al., (2013) reported that combination of salt (8\%), Citric acid (300ppm), potassium metabisulphite $(300 \mathrm{ppm})$ and sodium benzoate (300ppm) is the best hurdle treatment for low cost preservation of cauliflower. This treatment can extend the shelf life of cauliflower to 180 days when store at temperature between $3037^{\circ} \mathrm{C}$. The combination of hurdles osmotic dehydration, infrared drying, HDPE packaging and a radiation dose of $1 \mathrm{~kg}$ were proved to be effective in extending the shelf life of pineapple slices up to 4 months under ambient storage (Sujatha, 2014).

Gupta et al., found that Citric acid treatment in combination with gamma radiation and modified atmosphere packaging was employed as hurdles for control of 
microorganisms and extending shelf life of minimally processed French beans. Response surface methodology was used to optimize citric acid treatment and g-irradiation dose to obtain product with desired microbial and sensory quality. Optimum processing conditions (citric acid $8.4 \mathrm{~g} \mathrm{~L}$ L1; irradiation dose $0.7 \mathrm{kGy}$; 10_C) resulted in modified atmosphere of $18 \% \mathrm{O} 2$ and $4 \% \mathrm{CO} 2$ at end of storage period. Under these conditions shelf life of the product could be extended by one week with acceptable sensory and nutritional quality as evaluated by total antioxidant, phenolics, flavonoids and vitamin $\mathrm{C}$ content.

Cepero et al., (2006) investigated the effectiveness of the hurdle effect to increase the shelf life of fresh sausages. Two formulations were stored between 4 and $8^{0} \mathrm{C}$ at $93 \pm 5 \%$ of $\mathrm{RH}$ under two different conditions (hung in bars and vacuum packaged). Variants were studied for their physicochemical and sensory properties and microbiological quality; they were analysed weekly by an acceptable-refusal test, $\mathrm{pH}$ measures, and microbiological technique. Sensory analysis was considered as a refusal approach. Results indicated that it was possible to increase the shelf-life of the Cuban fresh sausage from 4 to 32 days using the following hurdle technology: vacuum packaging to decrease the oxidation-reduction potential, potassium sorbate as a preservative and low temperature (between 4 and $8^{\circ} \mathrm{C}$ ) during storage.

Kanatt et al., (2006) developed a process for the preparation of shelf-stable, ready-to-eat (RTE) shrimps using a combination of hurdles. The hurdles employed to cooked marinated shrimps included reduced water activity $(0.85 \pm 0.02)$, packaging and gamma radiation $(2.5 \mathrm{kGy})$. Microbiological analysis revealed a dose -dependent reduction in total viable count and Staphylococcus species. In nonirradiated samples a visible mold growth was seen within 15 days of storage at ambient temperature $\left(25 \pm 3^{0} \mathrm{C}\right)$. No Significant changes in textural properties and sensory qualities of the product were observed on radiation treatment. These RTE shrimps were microbiological safe and sensorially acceptable even after two months of storage at ambient temperature.

\section{Advantages of Hurdle Technology}

The greatest advantage of hurdle technology is tendency to conquer the ability of microorganisms in developing resistance to conventional preservation methods because in combine technology different preservative acts synergistically by hitting different targets within the cell of the spoilage microorganism. Hurdles are use at lower concentrations this prevent the undesired side effects, lower production cost and save energy. Another advantage is the opportunity of using natural preservatives in combination with synthetic preservatives, this also lower the risk associated with using synthetic preservatives at high concentration. Possibility of increasing shelf-stable foods; because food preserved by combined methods (hurdles) remains stable and safe even without refrigeration, and is high in sensory and nutritive value due to the gentle process applied (FOA, 2006).

\section{Disadvantages of Hurdle Technology}

Hurdle could have a negative effect on foods, depending on its intensity. For instance, chilling to low temperature is detrimental to some foods of plant origin (chilling injury), whereas moderate chilling will be beneficial for their shelf life. Another example is the $\mathrm{pH}$ of fermented sausage which should be low enough to inhibit pathogenic bacteria, but not so low to impair taste. If the intensity of a particular hurdle in a food is too small it should be strengthened, if it is detrimental to the food quality it should be lowered. By this 
adjustment, hurdles in foods can be kept in the optimal range, using safety as well as quality, and thus the total quality a food (Leistner, 2000). Jae et al., (2006) reported that addition of vinegar and sake lowered the hedonic scores of sous vide packaged seasoned beef.

Hurdle technology is an important approach that can be used to improve quality parameters during processing and storage of food. Smart application of hurdles improve sensory characteristics, chemical and microbiological qualities of food. More than 60 hurdles reported to be available, these can be use in different combinations and concentrations in wide range of foods. This versatility make the application of the technology possible in both modern and local food processing. (Leistner \& Gorris, 1995)

\section{References}

Abdullahi, N., Araihu, C. C. \& Abu, J. O., 2016. Effects of Chemical Hurdles and Packaging Materials on Microbial Load and Bacterial Distribution in Kilishi under Ambient Storage. International Journal of Engineering Research \& Technology, 5(8), pp. 306315.

Aditya, P. \& Nida, M., 2015. Hurdle Technology-An Approach towards Food Preservation. Int.J.Curr.Microbiol.App.Sci, 4(7), pp. 802-809.

Anurag, C., Sujatha, V., Ramesh, C. \& Babu, D. J., 2013. Development of Shelf Stable Intermediate Moisture Carrot (Daucus carota) Shreds Using Radiation as Hurdle Technology.. International Food Research Journal, 20(2), pp. 775-778.

Arora, A. K., Shashi, M. P. \& Sonney, S. K., 2014. Is chemical safety to food hazardous? Dangers of food preservatives. J Indian Acad Forensic
Med, 31(4).

Gunathilake, K., 2006. Application of Hurdles Techniques to preserve Fresh Scraped Coconut at Ambient and Refrigeration Storage. Journal of Natural Science Foundation, Sri Lanka, 33(4), pp. 265268.

Gupta, S. et al., 2012. Hurdle technology for shelf stable minimally processed French beans (Phaseolus vulgaris): A response surface methodology approach. Food Science and Technolog, Volume 48, pp. 182-189.

Hofstra, H., Vossen,. V. \& Plas, J. V., 1994. Microbes in Food Processing Technology, s.l.: Federation of European Microbiology Society..

José, A. U., Héctor, E. \& Lourdes, D., 2008. Colour Behaviour on Mango (Mangifera indica) Slices Self Stabilized in Glass Jars by Hurdle Technology during Storage. African Journal of Biotechnology, 7(4), pp. 487-494.

Leistner, L., 2010. Basic Aspects of Food Preservation by Hurdle Technology. International Journal of Food Microbiology, Volume 55, pp. 181186.

Leistner, L., 2011. Hurdle Technology. Encyclopedia of Life Support Systems (EOLSS), Food Engineering, Volume 3.

Oladapo, A. S., Akinyosoye, F. A. \& Abiodun, O., 2014. The Inhibitory effect of different Chemical Food Preservatives on the Growth of Selected Food Borne Pathogenic Bacteria. African Journal of Microbiology Research., 8(14), pp. 1510-1515.

Pokorn, J., 1994. Preservation of Fruit Juices. Food Preservation by Combined Processes., pp. 61,93.

Sujatha, V., 2014. Effect of Radiation in Combined Method as a Hurdle in 
Development of Shelf Stable Intermediate Moisture Pineapple (Ananas comosus). International Journal of Science and Technology,, 25(3), pp. 1736-1746.

Anon., 2005. International Food Information Service IFIS. In: Dictionary of Food Science and Technology. UK: Blackwell Publishing.

Anon., 2017. Food Safety and Quality Systems in Developing Countries, Volume 2.

Bazhal, M., Ngadi, M. \& Raghavan, G., 2003. Minimal Processing of Foods using Hurdle Technologies. The Canadian society for Engineering in Agriculture, Food and Biological System, pp. 03342.

G., S., 2013. Biologically Viable Methods for Food Preservation: A Review. Journal of Chemical and Environmental Sciences., 1(2), pp. 1-2.

Jae, D. J. et al., 2006. Hurdle Effect of Vinegar and Sake on Korean Seasoned Beef Preserved by Sous Vide Packaging. Food Control, pp. 171-175.

Jyoti, S., Ena, G. \& Ramesh, C., 2013. Low Cost Preservation of Cauliflower for 180 Days Through Hurdle Technology. International Journal of Food and Nutritional Sciences, 2(1).

K., J. V., 2003. Combining Traditional and
New Preservation Techniques to Control Pathogens : The Case of E. coli.. In: Food preservation techniques. Cambridge England: Woodhead Publishing Limited, pp. 205-206.

Leif, B., 1994. Discription of Hurdles. Final Report on Food-Linked AgroIndustrial Research, pp. 8-25.

Leistner, L. \& Gorris, L., 1995. Food Preservation by hurdle technology. In: Trend in Food Science and Technology. s.1.:s.n., pp. 35-37.

Leistner, L., 1978. Food quality and nutrition. s.l.:Applied Science Publishers.

Leistner, L., 2011. Hurdle Technology.. Encyclopedia of Life Support Systems (EOLSS), Food Engineering, Volume 3.

Lothar, L., 1997. Stable Hurdle Technology Foods and Packaging Worldwide. $J$. Pack. ScL Technol., 6(1).

Manual, F. a. A. O. T., 2006. Handling and Preservation of Fruits and Vegetables by Combined Methods for Rural Areas. FOA Agricultural Service Bulletin, pp. 1,146.

R., B., 2005. Fundamental Food Microbiology. 3 ed. London: CRC Press.

\section{How to cite this article:}

Ann Annie Shaju and Anjaly, M. G. 2021. Review on Effect of Hurdle Technology in Food Preservation. Int.J.Curr.Microbiol.App.Sci. 10(12): 169-176. doi: https://doi.org/10.20546/ijcmas.2021.1012.019 